\section{PROCEEDINGS B}

rspb.royalsocietypublishing.org

\section{Research}

Cite this article: Baniel A, Cowlishaw G, Huchard E. 2018 Jealous females? Female competition and reproductive suppression in a wild promiscuous primate. Proc. R. Soc. B 285: 20181332.

http://dx.doi.org/10.1098/rspb.2018.1332

Received: 15 June 2018

Accepted: 10 August 2018

\section{Subject Category:}

Behaviour

\section{Subject Areas:}

behaviour, evolution

\section{Keywords:}

reproductive suppression, paternal care, intrasexual competition, primate, chacma baboon

\section{Author for correspondence:}

Alice Baniel

e-mail: alice.baniel@gmail.com

Electronic supplementary material is available online at https://dx.doi.org/10.6084/m9.

figshare.c.4203110.

\section{Jealous females? Female competition and reproductive suppression in a wild promiscuous primate}

\author{
Alice Baniel11,2,3, Guy Cowlishaw ${ }^{3}$ and Elise Huchard ${ }^{2}$
${ }^{1}$ Institute for Advanced Study in Toulouse, Toulouse, France
${ }^{2}$ Institut des Sciences de I'Evolution de Montpellier, UMR 5554, CNRS, Université de Montpellier, Montpellier, France \\ ${ }^{3}$ Institute of Zoology, Zoological Society of London, London, UK
}

(iD) $\mathrm{AB}, 0000-0001-7142-5864$

Female-female competition over paternal care has rarely been investigated in promiscuous mammals, where discreet forms of male care have recently been reported despite low paternity certainty. We investigated female competition over paternal care in a wild promiscuous primate, the chacma baboon (Papio ursinus), where pregnant and lactating females establish strong social bonds (friendships) with males that provide care to their offspring. We tested whether pregnant and lactating females interfere with the sexual activity of their male friend to prevent new conceptions that might lead to the subsequent dilution of his paternal care. We found that pregnant and lactating females were more aggressive towards oestrous females when they had recently conceived themselves, and when the oestrous female was mate-guarded by, and showed greater sexual activity with, their male friend. This aggression also reduced the likelihood of conception of the targeted female. These findings indicate that females can aggressively prevent further conceptions with their offspring's carer through reproductive suppression. Competition over access to paternal care may play an important and underestimated role in shaping female social relationships and reproductive strategies in promiscuous mammalian societies.

\section{Introduction}

Traditional evolutionary models of paternal care assume that males should only provide care to their offspring when the degree of paternity certainty is high, typically in monogamous species $[1,2]$. Yet, recent empirical studies have indicated that male care can also evolve in promiscuous species where paternity confidence is lower, in particular when the cost of providing care is also low and does not compromise a male's future reproductive success [3,4]. For instance, males of several promiscuous primate species provide discreet forms of care to immatures, such as preferential affiliation, support during conflicts or tolerance at feeding sites (e.g. Barbary macaques, Macaca sylvanus: [5]; yellow baboons, Papio cynocephalus: [6]; olive baboons, Papio anubis: [7]; black-and-white snub-nosed monkeys, Rhinopithecus bieti: [8]). While males may provide care to unrelated infants to secure future mating opportunities with the mother [7,9], most studies indicate that males care for their genetic offspring, and assess their paternity probabilistically based on their mating history [10-12], or on their offspring's phenotypic resemblance to themselves [13].

According to evolutionary theories of parental investment [14], the more offspring a male sires, the more his care will be diluted between them, potentially leading mothers to compete for exclusive access to their mates [15]. For example, in facultatively polygynous birds, females breeding with polygynous males experience lower male investment and reproductive success than those breeding with monogamous males [15-17], and females that mate first aggressively exclude secondary-mated females from breeding units in order to maintain 
male monogamous matings [18]. In polygynous and promiscuous species more generally, where multiple females mate with a single male that provides paternal services, females that have already conceived may similarly attempt to prevent further conceptions with their mate, and the subsequent dilution of paternal care. To do so, they may harass those females that attempt to mate with him, either to interrupt copulations directly through mating interference and/or to induce chronic physiological stress that reduces their fertility (the 'reproductive suppression hypothesis' [19]).

So far, reproductive suppression has been mostly documented in cooperative breeders, where one or more dominant females use this mechanism to maximize the helper-topup ratio for their own offspring [20-22]. Reproductive suppression has been less well studied in groups of plural breeders where multiple females reproduce without helpers, but might similarly represent a manifestation of competition over offspring care provided by males. Mating interference and female-female harassment are commonplace in plural breeders [23], and some studies further suggest that the resulting stress can lower the reproductive success of rivals via physiological mechanisms [24]. For instance, some early studies in yellow baboons and geladas (Theropithecus gelada) indicate that subordinate females which are sexually receptive are regularly harassed by dominant females, and are also less fertile [25-27]. However, the determinants of female-female competition remain elusive in such studies, as well as whether the lower fertility of subordinate females is caused by harassment or by other rank-related differences between females.

Here, we tested the hypothesis that females which have already conceived attempt to prevent new conceptions with the carer of their offspring in a promiscuous primate species, the chacma baboon (Papio ursinus). Chacma baboons live in stable, multi-male-multi-female groups and breed year-round. During pregnancy and lactation, females form a strong social relationship (friendship) with a particular male $[28,29]$, usually the genetic father of their offspring [11,12]. Male friends will protect females and their offspring against aggression by conspecifics [6], which occasionally leads to infanticide [28] and feticide [30], and subsequently facilitate immature access to ecological resources [31]. Male reproductive skew is high in chacma baboons [32], which means that highranking males are usually involved in several simultaneous friendships. Female reproductive competition over paternal care appears likely in such societies, as high-ranking females aggressively displace subordinates from the proximity of their male friend [33], and aggression among lactating females peaks in periods of social instability when infanticide risk is elevated [34]. Moreover, alpha males form weaker bonds with their offspring than subordinate males [31], suggesting that each offspring indeed receives less care in the larger paternal sibships of alpha males. We test five predictions of the reproductive suppression over paternal care hypothesis, namely that pregnant and lactating females attempt to prevent oestrous females from copulating with their male friend by harassing them (prediction 1, P1), in particular when they have conceived themselves recently (P2) (given that synchronous females are expected to compete most intensely over access to male care); that the intensity of harassment correlates with the fertility (proximity of ovulation) of the oestrous female (P3) and with the intensity of her sexual activity with the male friend (P4) and that female-female aggression reduces the probability that the oestrous female conceives with the male friend (P5). (a) Study site and population

We studied wild chacma baboons at Tsaobis Nature Park, Namibia $\left(22^{\circ} 22^{\prime}\right.$ S $15^{\circ} 44^{\prime}$ E) (for details of the site and population, see [35]). We collected data on two habituated groups of baboons, called ' $\mathrm{J}$ ' and ' $\mathrm{L}$ ', over four different periods: JuneDecember 2005, May 2006-January 2007, June-October 2013 and May-November 2014. Group composition is given in the electronic supplementary material, table S1. Dominance ranks of adult males and females were established using both ad libitum and focal observations of dyadic agonistic interactions (electronic supplementary material, appendix S1).

\section{(b) Female reproductive state and mate-guarding}

\section{patterns}

The reproductive state of each female was monitored on a daily basis and categorized as follows: (i) pregnant, where pregnancy was determined post hoc following infant birth, and encompassed the six months since the conceptive cycle; (ii) lactation, if she had a dependent infant and had not yet resumed cycling, and (iii) in oestrus, if she was sexually receptive with a perineal swelling. Cycling non-swollen females were excluded from the analysis. Every day, trained observers recorded the swelling state (turgescent or deturgescent) and swelling size of oestrous females using a semiquantitative scoring system (from size 1 to 4 ). For each cycle, we defined the oestrous period as that time during which a swelling of any size was present, and the peri-ovulatory period (POP) as that time during which ovulation generally occurs, i.e. the 5-day period preceding (and excluding) the day of swelling detumescence [36]. For each cycle, we determined if it was conceptive or not by identifying a posteriori if a pregnancy occurred. The date of conception of pregnant and lactating females was estimated as the day following detumescence of the conceptive cycle (when witnessed) or determined post hoc by counting back six months from the date of birth, the gestation length of baboons [37]. Mate-guarding episodes, defined as periods when oestrous females are constantly followed by a male that mates exclusively with them and prevents others from doing so [38], were monitored ad libitum on a daily basis.

\section{(c) Behavioural data}

One hour focal animal samples were conducted on all adult females. In total, our sample comprises 2971 focal observations on 53 females distributed across reproductive states (electronic supplementary material, table S2). During focal observations, we continuously recorded aggressive incidents (attacks, chases, threats) and approach-avoid interactions (supplants, displacements) (for definitions, see the electronic supplementary material, appendix S1) involving the focal female, along with the identity of the receiver and initiator. In total, we observed 370 agonistic interactions initiated by pregnant or lactating females towards oestrous females. In 2013-2014, we also recorded all occurrences of male support towards oestrous females following female aggression. In addition, we recorded every occurrence of male-female grooming bouts, sexual solicitations ('presenting', when oestrous females present their hindquarters to males) and copulations, along with the identity of the male. We also noted all approaches and departures within $1 \mathrm{~m}$ between the focal individual and any other adult female (to calculate the time spent in close proximity between female dyads during a focal observation). Finally, we conducted proximity scans every $5 \mathrm{~min}$ to record the identity and distance of the nearest male neighbour.

\section{(d) Identification of heterosexual friendships}

The male friend of each pregnant and lactating female was identified using a combination of spatial proximity and 
grooming allocation indices. Full details can be found in the electronic supplementary material, appendix S2. In short, a male was considered as a friend of a given pregnant/lactating female if he was both her most frequent nearest neighbour and her most frequent grooming partner, and if he had an outstandingly high score in both indices compared to other males (i.e. if his score is at least twice as high as those of other males) [29]. Using this criterion, a female would have either one or two male friend(s) or, in the case of undifferentiated relationships with males, no friend. Overall, we identified at least one male friend for $83 \%$ of pregnant and lactating females $(n=67$ out of 81$)$.

\section{(e) Statistical analysis}

We ran binomial generalized linear mixed-effect models (GLMMs) using the glmer function of the lme4 package [39] in R v. 3.4.1 [40]. Technical details on how GLMMs were run and how the significance of variables was tested are described in the electronic supplementary material, appendix S3.

\section{(f) Are females more likely to exhibit aggression towards oestrous females that are mate-guarded by their male friend?}

We first investigated whether pregnant and lactating females involved in a friendship direct more aggression towards oestrous females that are mate-guarded by their male friend, compared to when they are unguarded or mate-guarded by a different male (P1), and when they are in closer reproductive synchrony, compared to when they are less synchronous (P2). For each focal observation, we created a list of all possible dyadic combinations of initiators and receivers involving the focal female (e.g. for female $A$ in an entire group including only two other females, $\mathrm{B}$ and $\mathrm{C}: \mathrm{A} \rightarrow \mathrm{B}, \mathrm{A} \rightarrow \mathrm{C}, \mathrm{B} \rightarrow \mathrm{A}, \mathrm{C} \rightarrow \mathrm{A})$. We then restricted this dataset to dyads where receivers were in oestrous and initiators were pregnant or lactating. We created a binary variable 'aggression' which recorded whether a directional agonistic interaction occurred in those dyads during the focal observation. We ran a binomial GLMM using the occurrence of aggression received by oestrous females from pregnant/lactating females during a focal observation as the response variable. Random effects comprised the identity of the initiator and receiver, as well as the identity of the focal observation. The fixed effects comprised the following.

- An index of reproductive synchrony between the initiator and the receiver of the dyad (in days). This index was calculated as the absolute difference in days between the initiator's conception date and the focal observation date, and measures the potential reproductive synchrony should the oestrous female conceive on that focal day.

- The 'mate-guarding status' of the receiver, with three levels: 'guarded by the friend' if the receiver was guarded by the male friend of the initiator, 'guarded by a different male' if the receiver was guarded by another male and 'unguarded' if the receiver was not guarded by any male. Cases where the receiver was guarded by a male and the initiator had no friend were categorized as 'guarded by a different male'.

- The interaction between the index of potential reproductive synchrony and mate-guarding status, in order to test whether potential reproductive synchrony is more important when the receiver is mating with the initiator's friend than in other cases.

- An index of spatial proximity between the initiator and the receiver of the dyad (to control for the fact that two females sharing the same male might attack each other more often just because they spend more time in proximity). This index was calculated as the time spent within $1 \mathrm{~m}$ of each other during the focal observation (calculated using approaches and departures within $1 \mathrm{~m}$ ).

- The relative dominance rank of the initiator and receiver (as two fixed effects).

- Group identity (by including group identity as a fixed effect, we do not seek to systematically assess group effects, which would require a larger sample with targeted observations, but rather control for such effects should any be present). - Year.

\section{(g) Are females more likely to exhibit aggression} towards oestrous females that are closer to conception and copulate more frequently with their male friend?

We tested whether aggression received by an oestrous female from the female friends of a male (pregnant or lactating) increased with her probability of conception (P3), and the intensity of her sexual activity with this male (P4), using a binomial GLMM. For each focal observation of an oestrous female, we identified all possible dyads involving this female and all resident males that have at least one female friend, and calculated the response variable as the occurrence of aggression received by that oestrous female from the female friends (pregnant or lactating) of each male (yes/no). Random effects comprised the identity of the focal female, the male and the focal observation. Fixed factors comprised the following.

- An index of fertility measured by proximity from the POP, as a continuous measure, in days. This measure was used because the probability of ovulation increases gradually through the oestrus period until reaching a peak in the 5 days preceding the day of detumescence, which is easy to identify visually [36]. This index was therefore set to 0 in the 5 days preceding detumescence (i.e. the POP), to 1 in the first day preceding the POP, to 2 in the second day preceding the POP, etc. The day of detumescence was set to 1 (i.e. coded similarly to the first day preceding the POP).

- The rate of sexual activity of the focal female with the male considered during the focal observation (i.e. the number of presentings and copulations per hour).

- The mate-guarding status of the oestrous female (guarded by the male/unguarded: 1/0).

- The interaction between the rate of sexual activity and mateguarding status, in order to test whether the effect of sexual activity is more important when the oestrous female is mate-guarded by the male friend.

- An index of spatial proximity between the focal female and female friends of a male (to control for the fact that female friends might attack an oestrous female more often because she spends more time around them). This index was calculated as the cumulative time that oestrous females spent within $1 \mathrm{~m}$ of any female friend of a male during the focal observation.

- The relative rank of the oestrous female.

- The relative rank of the male friend.

- Group identity and year.

\section{(h) Can females decrease the chance that their male friend conceives with an oestrous female by} harassing her?

We then tested whether the probability of conception between an oestrous female and her mate-guarding male decreased when the oestrous female received higher rates of aggression from the female friends of the male throughout the oestrus period (P5). 
Table 1. Influence of reproductive synchrony and sharing of the same male partner on the probability of agonistic interactions received by oestrous females from pregnant/lactating females. (Parameters and tests are based on 2366 focal observations and 276 occurrences of aggressive interactions distributed among 50 initiators and 40 receivers. GLMMs control for focal observation identity, initiator and receiver identity (fitted as random factors). The confidence interval (Cl) and $p$-value of statistically significant results are highlighted in italics. s.e., standard error; LRT, statistic of a likelihood ratio test; d.f., degrees of freedom.)

\begin{tabular}{|c|c|c|c|c|c|c|c|c|}
\hline response variable & fixed factor & levels & estimate & s.e. & $95 \% \mathrm{Cl}$ & LRT & d.f. & $p$-value \\
\hline \multirow{11}{*}{$\begin{array}{l}\text { probability that oestrous } \\
\text { females receive aggression } \\
\text { from the female friends of a } \\
\text { male }(0 / 1) \text {, by female - } \\
\text { female dyad }\end{array}$} & $\begin{array}{l}\text { reproductive } \\
\text { synchrony }\end{array}$ & & -0.45 & 0.22 & $(-0.89 ;-0.03)$ & 4.51 & 1 & 0.034 \\
\hline & \multirow[t]{3}{*}{$\begin{array}{l}\text { male sharing } \\
\text { status }\end{array}$} & $\begin{array}{l}\text { same male (ref: } \\
\text { no male) }\end{array}$ & 0.75 & 0.18 & $(0.40 ; 1.10)$ & 38.65 & 2 & $<0.001$ \\
\hline & & $\begin{array}{l}\text { same male (ref: } \\
\text { different male) }\end{array}$ & 1.46 & 0.24 & $(0.99 ; 1.94)$ & & & \\
\hline & & $\begin{array}{l}\text { different male (ref: } \\
\text { no male) }\end{array}$ & -0.70 & 0.20 & $(-1.11 ;-0.32)$ & & & \\
\hline & $\begin{array}{l}\text { spatial } \\
\text { proximity }\end{array}$ & & 0.24 & 0.07 & $(0.08 ; 0.37)$ & 7.91 & 1 & 0.005 \\
\hline & rank initiator & & 1.54 & 0.25 & $(1.05 ; 2.07)$ & 29.63 & 1 & $<0.001$ \\
\hline & rank receiver & & -1.06 & 0.21 & $(-1.57 ;-0.69)$ & 25.64 & 1 & $<0.001$ \\
\hline & group $^{a}$ & L & 0.57 & 0.27 & $(0.03 ; 1.13)$ & 4.27 & 1 & 0.039 \\
\hline & \multirow[t]{3}{*}{ year $^{\mathrm{b}}$} & 2006 & 0.37 & 0.35 & $(-0.30 ; 1.09)$ & 14.38 & 3 & 0.002 \\
\hline & & 2013 & -0.70 & 0.42 & $(-1.54 ; 0.12)$ & & & \\
\hline & & 2014 & 0.29 & 0.36 & $(-0.43 ; 1.00)$ & & & \\
\hline
\end{tabular}

aReference category: J group.

${ }^{\text {b}}$ Reference category: 2005.

Only cycles for which we had more than $4 \mathrm{~h}$ of observations of the oestrus period were included (mean \pm s.d. hours of observation per cycle: $16.42 \pm 16.42$ ). For each oestrus cycle of each female, we identified the male that mate-guarded her during her POP (i.e. with whom she may conceive). For 17 out of 60 cycles, females had several mate-guarding males in her POP; in these cases, we only kept cycles during which one male monopolized 4 days out of 5 of the POP ( 11 out of 17 cycles) and omitted secondary mate-guarding episodes which were less likely to be conceptive. For females guarded by males who did not have any female friend, the rate of aggression was set at zero. We then ran a binomial GLMM using the probability of conception of each cycle (conceptive/not conceptive: 1/0) as the response variable. Random effects comprised the identities of the oestrous female and the male. The fixed factors comprised the following.

- The rate of aggression received by the oestrous female from the female friends of the male throughout the oestrus period (calculated as the total number of aggressive interactions received by the focal female from the female friends of a male throughout her oestrus cycle, divided by the corresponding observation time).

- The rate of aggression received by the oestrous female from any other adult female of the group (calculated as the total number of aggressive interactions received by the focal female from any non-friend female of a male throughout her oestrus cycle, divided by the corresponding observation time) to control for a potential confounding effect of female-female aggression at the group level on the chance that the focal female conceives.

- Whether the cycle was the first postpartum cycle (yes/no) because females experience reduced fertility in the first cycle following lactational amenorrhoea [41])

- The relative rank of the oestrous female and of the male (over the oestrus period).

\section{Results}

Male mating skew was high in both social groups during our study period (see the electronic supplementary material, appendix S4), and male mating success was highly correlated with male dominance rank (see the electronic supplementary material, appendix S5). Moreover, resident males had zero to nine pregnant and lactating female friends simultaneously (electronic supplementary material, table S3), setting up conditions that may favour female competition over access to male care.

\section{(a) Are females more likely to exhibit aggression towards oestrous females that are mate-guarded by their male friend?}

As expected under P1, pregnant and lactating females were more likely to be aggressive towards oestrous females that were mate-guarded by their male friend (mean dyadic rate \pm s.d.: $0.07 \pm 0.35$ time $h^{-1}$ ), than towards unguarded females $(0.03 \pm 0.18)$ or females guarded by another male $(0.01 \pm 0.13)$ (table 1 and figure $1 a)$, even when controlling for the fact that females sharing the same male spend more time in close proximity. Furthermore, pregnant and lactating females that had conceived more recently were more likely to be aggressive towards oestrous females (P2) (table 1 and figure $1 b$ ), though this effect of reproductive synchrony was not greater when the oestrous female was mate-guarded by their male friend than when unguarded or guarded by another male (interaction between reproductive synchrony and male sharing status: $\chi_{2}^{2}=1.45, p=0.485$ ). 
(a)

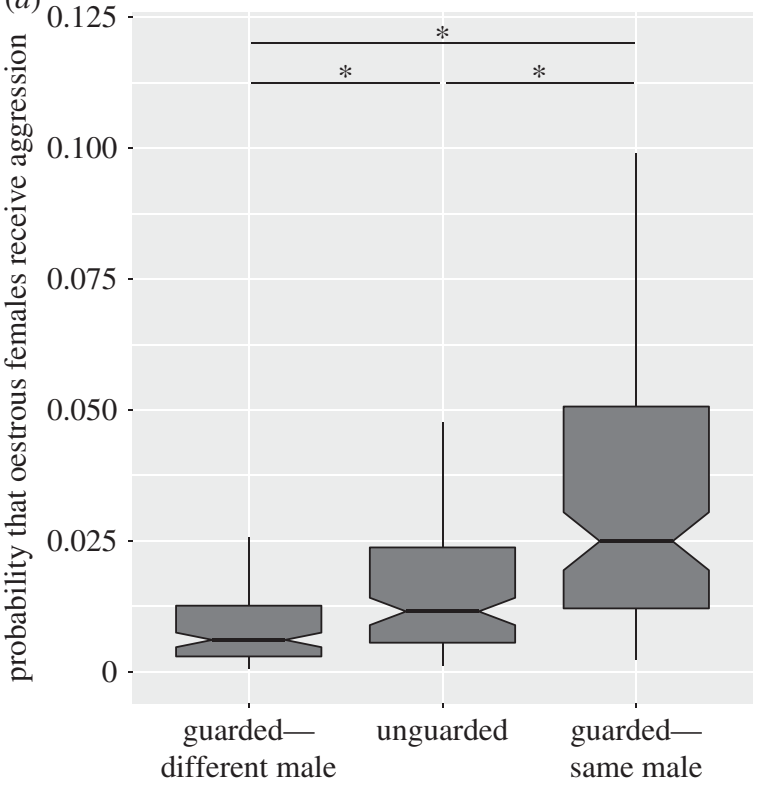

male sharing status between initiators and receivers

(b)

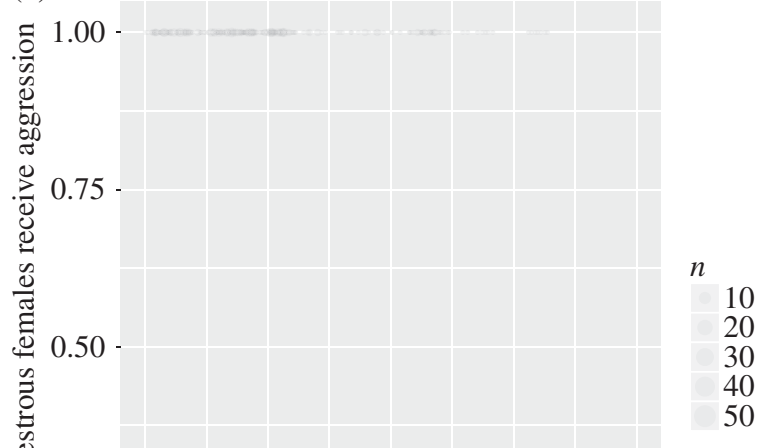

Figure 1. Predicted probability that oestrous females receive aggression from pregnant and lactating females, according to $(a)$ their male sharing status and $(b)$ thei reproductive synchrony. In (a), boxplots are drawn from the distribution of the predicted probabilities, while varying the rank of actors and receivers between 0 and 1 , and using the mean for other numerical values (for a reproductive synchrony of 259 days and a time in proximity of $0.21 \mathrm{~min}$ ), in J troop in 2014 for categorical variables. Comparisons between the different levels of the variable 'male sharing status' are denoted by an asterisk if statistically significant. In (b), the solid line is the model prediction, and the dotted lines represent the $95 \%$ confidence interval. The prediction line is drawn for a dyad sharing a male, that spends 0.21 min in proximity, where the initiator has rank 1 and receiver has rank 0.5, in J group, in 2014. The grey dots represent the raw data of whether an aggression was exchanged (1) or not (0) within the dyad, and their size is proportional to the number of occurrences in the dataset.

\section{(b) Are females more likely to exhibit aggression towards oestrous females that are closer to conception and copulate more frequently with their male friend?}

Oestrous females were more likely to receive aggression from the pregnant and lactating female friends of their sexual partner when they presented to him and copulated with him more often (P4) (table 2 and figure 2a). This was true for both mate-guarded and unguarded females (the interaction between mate-guarding status and the rate of sexual activity was not significant: $\chi_{1}^{2}=2.63, p=0.105$ ), and when controlling for spatial proximity between the oestrous female and the female friends of her mate. Aggression was also more likely when the male partner had more female friends, but unaffected by the fertility of the oestrous female, estimated via her proximity to ovulation (contrary to P3).

\section{(c) Can females decrease the chance that their male friend conceives with an oestrous female by harassing her?}

Oestrous females received twice as much aggression from the female friends of their mate-guarding male in non-conceptive cycles (mean \pm s.d. amount of aggression received: $0.13 \pm 0.19$, $n=31$ cycles $)$ than in conceptive cycles $\left(0.07 \pm 0.13\right.$ time $^{-1}$, $n=20$ cycles). The probability of conception of an oestrous female thus decreased when she faced more aggression from the female friends of her mate (P5), but remained unaffected by aggression received from other female group-mates (table 3 and figure $2 d$ ). Females were also more likely to conceive with high-ranking males. The observed association between lower aggression and a greater likelihood of conception might also arise if mate-guarding males more actively protected oestrous females during aggressive interactions with other females during conceptive cycles. However, we assessed the occurrence of male protection of oestrous females (in 2013-2014), and male support was involved in only nine of 144 aggressive incidences initiated by a pregnant or lactating female towards an oestrous female (including six from the mate-guarding male and three from other males). Moreover, only one of these cases occurred during a conceptive cycle. Males therefore rarely intervened in conflicts among females, regardless of their fertility.

\section{Discussion}

High rates of female aggression towards oestrous females have previously been reported in this $[34,42]$ and other populations of cercopithecids [25-27], raising the question of whether it represents reproductive suppression. These new analyses extend these studies by showing that the aggressors include the pregnant and lactating females associated with their male mating partner (who is the likely father of, and carer to, their offspring). This aggression increases with the sexual activity of the mating couple, and is most likely to occur when the associated females have conceived more recently and are therefore more vulnerable to the future dilution of paternal care, especially protection from infanticidal attacks (which are most common in the first six months of an infant's life [43]). Most importantly, we found that oestrous females were less likely to conceive during those cycles when they received more aggression from the female friends of their mate-guarding male. Taken together, these patterns suggest that females who have already conceived aggressively target 
(a)

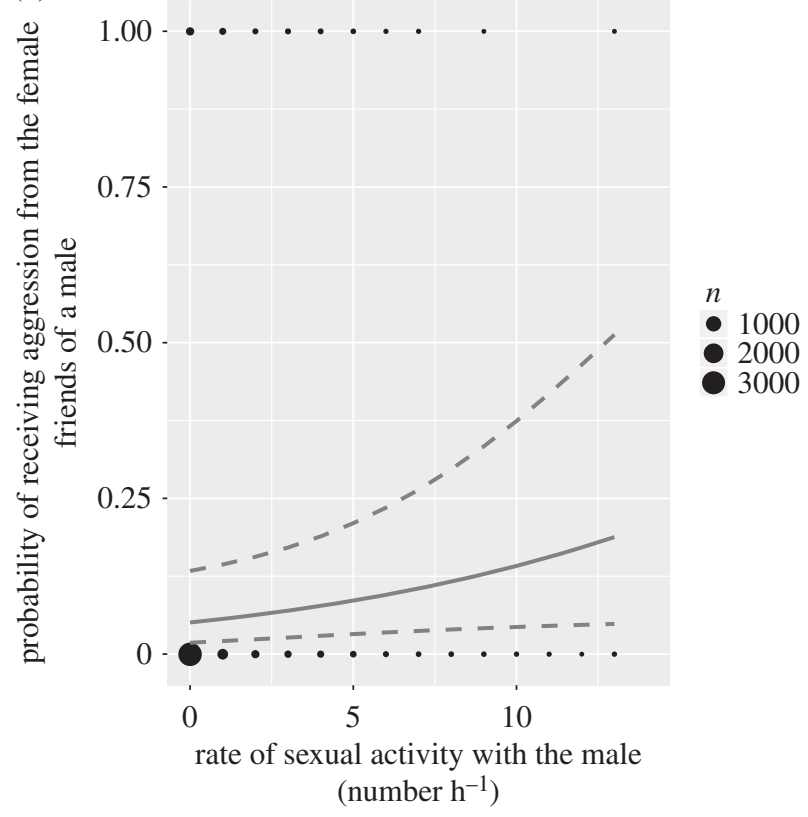

(b)

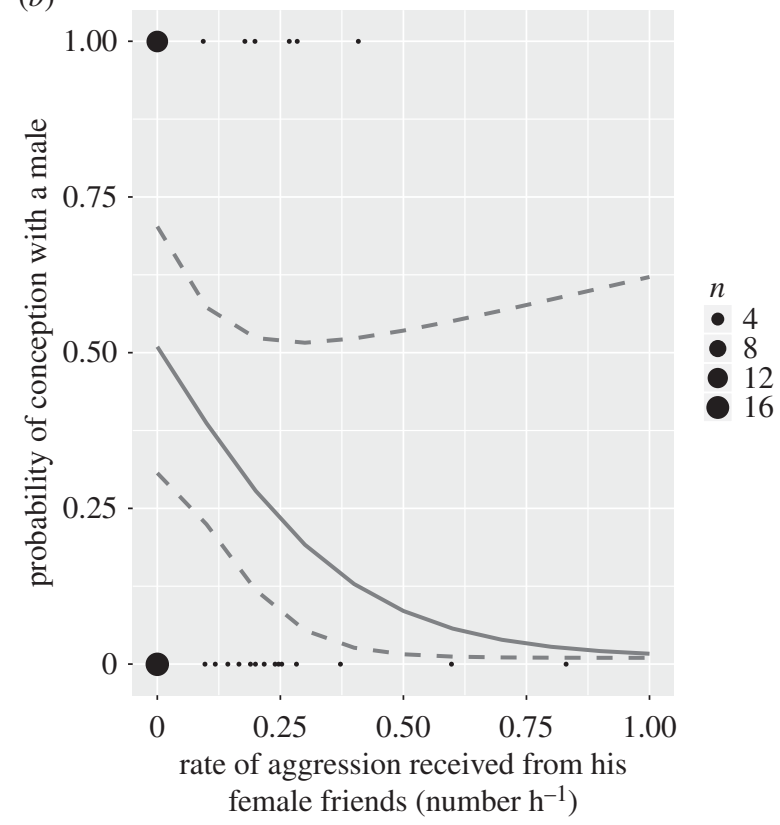

Figure 2. Predicted probability that oestrous females (a) receive aggression from the female friends of a male, according to their sexual activity with the male and (b) conceive with a male according to the rate of aggression received from the female friends during the oestrus period. Solid lines represent the model predictions and the dotted lines the $95 \%$ confidence interval. In (a), the prediction line is drawn holding all other fixed effects constant, using the mean for numeric variables (for a mate-guarded oestrous female of rank 0.53 , that spends $0.37 \mathrm{~min}$ in proximity of the female friends, 7 days before the POP, and a male of rank 0.67 , having 2.15 female friends), in J group, in 2014 for categorical variables. In (b), the prediction line is drawn using the mean ranks for female and male $(0.57$, and 0.79 , respectively) and the mean rate of aggression from other females $\left(0.28\right.$ aggressive act $\left.\mathrm{h}^{-1}\right)$. The black dots represent the raw data: whether aggression was exchanged (1) or not $(0)$ in $(a)$, and whether conception occurred (1) or not $(0)$ in $(b)$, and their size is proportional to the number of occurrences in the dataset.

Table 2. Influence of the sexual activity of oestrous females with a male on the probability that they receive aggression from the pregnant/lactating females involved in a friendship with him. (Parameters and tests are based on 1262 focal observations of oestrous females, distributed among 35 focal females and 27 males. We observed 1569 occurrences of sexual activity (587 copulations, 982 presentings), and 199 occurrences of aggression between oestrous females and pregnant/lactating female friends. GLMMs control for focal observation identity, focal female and male identity (fitted as random factors). The confidence interval (Cl) and p-value of statistically significant results are highlighted in italics. s.e., standard error; LRT, statistic of a likelihood ratio test; d.f., degrees of freedom.)

\begin{tabular}{|c|c|c|c|c|c|c|c|c|}
\hline response variable & fixed factor & levels & estimate & s.e. & $95 \% \mathrm{Cl}$ & LRT & d.f. & $p$-value \\
\hline \multirow{11}{*}{$\begin{array}{l}\text { probability that oestrous } \\
\text { females receive aggression } \\
\text { from the female friends } \\
\text { of a male }(0 / 1) \text {, across } \\
\text { male friends }\end{array}$} & $\begin{array}{l}\text { sexual activity } \\
\text { (presentings, } \\
\text { copulations) }\end{array}$ & & 0.27 & 0.13 & $(0.00 ; 0.53)$ & 3.87 & 1 & 0.049 \\
\hline & $\begin{array}{l}\text { mate-guarding with the } \\
\text { male }^{\mathrm{a}}\end{array}$ & & 0.71 & 0.27 & $(0.18 ; 1.24)$ & 6.83 & 1 & 0.009 \\
\hline & proximity to ovulation & & 0.23 & 0.20 & $(-0.16 ; 0.62)$ & 1.35 & 1 & 0.246 \\
\hline & $\begin{array}{l}\text { number of female friends } \\
\text { of male }\end{array}$ & & 1.32 & 0.24 & $(0.86 ; 1.80)$ & 30.76 & 1 & $<0.001$ \\
\hline & $\begin{array}{l}\text { spatial proximity with } \\
\text { female friends }\end{array}$ & & 0.21 & 0.10 & $(-0.00 ; 0.41)$ & 3.70 & 1 & 0.054 \\
\hline & rank of focal female & & -1.03 & 0.26 & $(-1.65 ;-0.58)$ & 18.50 & 1 & $<0.001$ \\
\hline & rank of male & & 0.14 & 0.30 & $(-0.45 ; 0.74)$ & 0.23 & 1 & 0.635 \\
\hline & group ${ }^{b}$ & $\mathrm{~L}$ & 0.73 & 0.47 & $(-0.26 ; 1.69)$ & 2.20 & 1 & 0.138 \\
\hline & yearc $^{c}$ & 2006 & 0.34 & 0.41 & $(-0.45 ; 1.22)$ & 9.04 & 3 & 0.029 \\
\hline & & 2013 & -0.69 & 0.72 & $(-2.13 ; 0.75)$ & & & \\
\hline & & 2014 & 0.70 & 0.58 & $(-0.46 ; 1.91)$ & & & \\
\hline
\end{tabular}

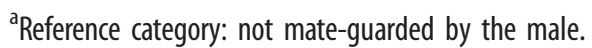

beference category: J group.

'Reference category: 2005. 
Table 3. Influence of aggression received by oestrous females from the female friends of a male throughout their oestrus periods on the probability of conceiving with this male subsequently. (Parameters and tests are based on 51 oestrous cycles (out of which 20 were conceptive) distributed among 29 focal oestrous females and 18 males. GLMMs control for focal female and male identity (fitted as random factors). The confidence interval (Cl) and $p$-value of statistically significant results are highlighted in italics. s.e., standard error; LRT, statistic of a likelihood ratio test; d.f., degrees of freedom.)

\begin{tabular}{|c|c|c|c|c|c|c|c|}
\hline response variable & fixed factor & estimate & s.e. & $95 \% \mathrm{Cl}$ & LRT & d.f. & $p$-value \\
\hline \multirow[t]{5}{*}{$\begin{array}{l}\text { probability of conception } \\
\text { during a given cycle }(0 / 1)\end{array}$} & $\begin{array}{l}\text { aggression received from female } \\
\text { friends during oestrus cycle }\end{array}$ & -1.72 & 1.02 & $(-4.06 ;-0.04)$ & 4.07 & 1 & 0.044 \\
\hline & $\begin{array}{l}\text { aggression received from other } \\
\text { females during oestrus cycle }\end{array}$ & 1.01 & 0.82 & $(-0.48 ; 2.84)$ & 1.76 & 1 & 0.185 \\
\hline & first postpartum cycle (yes/no) & -0.62 & 0.82 & $(-2.36 ; 0.94)$ & 0.59 & 1 & 0.441 \\
\hline & rank of focal female & -0.10 & 0.74 & $(-1.59 ; 3.12)$ & 0.02 & 1 & 0.889 \\
\hline & rank of the male & 2.65 & 1.05 & $(0.91 ; 5.68)$ & 10.51 & 1 & 0.001 \\
\hline
\end{tabular}

${ }^{a}$ Aggression has been calculated as the number of aggressive interactions that the focal female received throughout her oestrus period divided by the corresponding observation time.

oestrous females who attempt to mate with their offspring's father to prevent him from conceiving again, which may lead to the loss of paternal services for their own offspring. In mammals, evidence for reproductive suppression among females primarily comes from cooperative breeders where dominant females monopolize reproduction to maximize the amount of allomaternal care received by their offspring. This study reveals a new form of reproductive suppression in a promiscuous primate society where all females breed and where males provide discreet paternal care, but the ultimate determinant seems to be essentially similar to cooperative breeders: to obtain more help to raise offspring.

Our interpretation assumes the dilution of paternal care among paternal siblings. Although this assumption is central to paternal investment theory [14], it may not hold in promiscuous primates where the cost of paternal care is presumably low, as some forms of paternal care appear essentially passive. For example, spatial proximity between lactating females and their male friend is almost exclusively maintained by the female, while the male simply appears to tolerate their presence $[12,28]$. However, additional studies suggest that male care may in fact be more costly than it seems. Playback experiments show that males readily respond to a distress call from a female friend by running towards her to provide social support [28] and anecdotal reports show that fathers will engage in severe fights with rivals that pose an infanticidal threat to their offspring [12]. Fights among adult male baboons may incur severe to lethal injuries, suggesting that offspring protection can be associated with life-threatening risks from a male's perspective. It is therefore plausible that males may be less willing to risk their life when they care for several dependent offspring, if only because their capacity to protect the remaining offspring will be compromised if they are injured or die when defending an infant. In line with this, subordinate males, who sire fewer offspring than dominants, also form closer bonds with their offspring [31]. That said, the paternal care dilution hypothesis has never been formally tested in promiscuous primates and certainly deserves further investigation.

The exact mechanisms linking female harassment and reproductive suppression in baboons remain unknown. Reproductive suppression could be mediated by direct mating interference, given that pregnant and lactating females attack oestrous females more frequently when they show higher levels of sexual activity. Such aggression may inhibit the sexual activity of oestrous females, particularly subordinates. However, copulations still occur at a high frequency during mate-guarding episodes, suggesting that mating interference alone is unlikely to explain the observed decline in fertility, and that physiological stress may play a critical role. High rates of aggression and elevated levels of cortisol have been found to disrupt ovulation and the secretion of sex hormones in several captive primates [24,44], and to cause implantation failure in hamsters [45]. This interpretation is also consistent with our finding that pregnant and lactating females harass oestrous females not just at the time of ovulation but throughout the oestrus cycle.

Our results suggest that paternal care may be an important determinant of female competitive relationships in promiscuous primate societies, with wider implications for our understanding of female reproductive competition across mating systems. In the case of demography, the ability of some females to suppress synchronous breeding by others may lead to a staggering of births that could help to explain why some species, like baboons, breed year-round despite living in seasonal environments [46]. Similarly, the prevalence of sexual ornaments in oestrous females from promiscuous primate species (e.g. facial coloration [47], copulatory calls [48] and exaggerated sexual swellings [49]) probably reflects the intensity of competition faced by females to be chosen by males, despite a typically male-biased sex ratio. This study adds new evidence to the idea that these females ultimately compete over access to male care $[50,51]$.

Ethics. Our research procedures were evaluated and approved by the Ethics Committee of the Zoological Society of London and the Ministry of Environment and Tourism (MET), Namibia, and adhered to the ASAB/ABS Guidelines for the Treatment of Animals in Behavioural Research and Teaching. Our research was conducted under MET permit nos. 886/2005, 1039/2006, 1786/2013 and 1892/2014. Data accessibility. Data are available through the public repository GitHub at: https://github.com/AliceBaniel/Reproductive-suppression-chacma-baboon

Authors' contributions. A.B. and E.H. designed the study and collected the data. A.B. performed the analyses. All authors contributed to the drafting of the manuscript.

Competing interests. We declare we have no competing interests.

Funding. A.B. benefited from financial support from the Agence Nationale de la Recherche Labex IAST, the Ministère de l'Education 
Nationale, de l'Enseignement Supérieur et de la Recherche, the Primate Society of Great Britain, and the Fondation des Treilles.

Acknowledgements. We are grateful to the Tsaobis Baboon Project volunteers in 2005-2006 and 2013-2014 for invaluable help in the field, and to three anonymous reviewers for very helpful comments on the manuscript. Thanks to the Tsaobis beneficiaries for permission to work at Tsaobis Nature Park, the Gobabeb Research and Training Centre for affiliation, the Ministry of Environment and Tourism for research permits, and to the Snyman and Wittreich families for permission to work on their land. This paper is a publication of the ZSL Institute of Zoology's Tsaobis Baboon Project. Contribution ISEM 2018-158.

\section{References}

1. Kleiman DG, Malcolm JR. 1981 The evolution of male parental investment in mammals. In Parental care in mammals (eds DJ Gubernick, PH Klopfer), pp. 347-387. New York, NY: Plenum Publishing Corporation.

2. Clutton-Brock TH. 1991 The evolution of parental care. Princeton, NJ: Princeton University Press.

3. Griffin AS, Alonzo SH, Cornwallis CK. 2013 Why do cuckolded males provide paternal care? PLOS Biol. 11, e1001520. (doi:10.1371/journal.pbio.1001520)

4. Alonzo SH, Klug H. 2012 Paternity, maternity, and parental care. In The evolution of parental care (eds NJ Royle, PT Smiseth, M Kölliker), pp. 189-205. Oxford, UK: Oxford University Press.

5. Paul A, Kuester J, Arnemann J. 1996 The sociobiology of male-infant interactions in Barbary macaques, Macaca sylvanus. Anim. Behav. 51, 155-170. (doi:10.1006/anbe.1996.0013)

6. Buchan JC, Alberts SC, Silk JB, Altmann J. 2003 True paternal care in a multi-male primate society. Nature 425, 179-181. (doi:10.1038/nature01866)

7. Smuts BB. 1985 Sex and friendship in baboons. New York, NY: Aldine.

8. Xiang Z, Sayers K, Grueter C. 2009 Direct paternal care in blackand-white snub-nosed monkeys.

J. Zool. 278, 157-162. (doi:10.1111/j.1469-7998. 2009.00563.x)

9. Ménard N, von Segesser F, Scheffrahn W, Pastorini J, Vallet D, Gaci B, Martin RD, Gautier-Hion A. 2001 Is male-infant caretaking related to paternity and/or mating activities in wild Barbary macaques (Macaca sylvanus). C. R. Acad. Sci. Ser. III Sci. la Vie 324, 601-610.

10. Lehmann J, Fickenscher G, Boesch C. 2007 Kin biased investment in wild chimpanzees. Behaviour 143, 931-955. (doi:10.1163/ 156853906778623635)

11. Moscovice LR, Di Fiore A, Crockford C, Kitchen DM, Wittig R, Seyfarth RM, Cheney DL. 2010 Hedging their bets? Male and female chacma baboons form friendships based on likelihood of paternity. Anim. Behav. 79, 1007-1015. (doi:10.1016/j.anbehav. 2010.01.013)

12. Huchard E, Alvergne A, Fejan D, Knapp LA, Cowlishaw G, Raymond M. 2010 More than friends? Behavioural and genetic aspects of heterosexual associations in wild chacma baboons. Behav. Ecol. Sociobiol. 64, 769-781. (doi:10.1007/s00265-0090894-3)

13. Widdig A. 2007 Paternal kin discrimination: the evidence and likely mechanisms. Biol. Rev. 82, 319-334. (doi:10.1111/j.1469-185X.2007. 00011.x)
14. Trivers RL. 1972 Parental investment and sexual selection. In Sexual selection and the descent of man (ed. P Campbell), pp. 136-179. London, UK: Heinemann.

15. Slagsvold T, Lifjeld JT. 1994 Polygyny in birds: the role of competition between females for male parental care. Am. Nat. 143, 59-94. (doi:10.1086/ 285596)

16. Smith HG, Ottosson U, Sandell MI. 1994 Intrasexual competition among polygynously mated female starlings (Sturnus vulgaris). Behav. Ecol. 5, 57-63. (doi:10.1093/beheco/5.1.57)

17. Sandell MI, Smith HG. 1996 Already mated females constrain male mating success in the European starling. Proc. R. Soc. B 263, 743-747. (doi:10. 1098/rspb.1996.0111)

18. Sandell Ml. 1998 Female aggression and the maintenance of monogamy: female behaviour predicts male mating status in European starlings. Proc. R. Soc. B 265, 1307-1311. (doi:10.1098/rspb. 1998.0434)

19. Young AJ. 2009 The causes of physiological suppression in vertebrate societies: a synthesis. In Reproductive skew in vertebrates: proximate and ultimate causes (eds R Hager, (B Jones), pp. 397-436. Cambridge, UK: Cambridge University Press.

20. Clutton-Brock TH, Hodge SJ, Spong G, Russell AF, Jordan NR, Bennett NC, Sharpe LL, Manser MB. 2006 Intrasexual competition and sexual selection in cooperative mammals. Nature 444, 1065-1068. (doi:10.1038/nature05386)

21. Clutton-Brock TH, Hodge SJ, Flower TP, Spong GF, Young AJ. 2010 Adaptive suppression of subordinate reproduction in cooperative mammals. Am. Nat. 176, 664-673. (doi:10.1086/656492)

22. Clutton-Brock TH, Russell AF, Sharpe LL, Brotherton PNM, Mcllrath GM, White S, Cameron EZ. 2001 Effects of helpers on juvenile development and survival in meerkats. Science 293, 2446-2449. (doi:10.1126/science.1061274)

23. Dixson AF. 1998 Primate sexuality. Comparative studies of the prosimians, monkeys, apes, and human beings. Oxford, UK: Oxford University Press.

24. Beehner JC, Lu A. 2013 Reproductive suppression in female primates: a review. Evol. Anthropol. 22, 226-238. (doi:10.1002/evan.21369)

25. Dunbar RIM. 1980 Determinants and evolutionary consequences of dominace among female gelada baboons. Behav. Ecol. Sociobiol. 7, 253-265. (doi:10.1007/BF00300665)

26. Wasser SK, Starling AK. 1988 Proximate and ultimate causes of reproductive suppression among female yellow baboons at Mikumi National Park, Tanzania. Am. J. Primatol. 16, 97-121. (doi:10. 1002/ajp.1350160202)

27. Wasser SK, Starling AK. 1995 Reproductive competition among female yellow baboons. In Primate ontogeny, competition and social behaviour (eds JG Else, PC Lee), pp. 343-354. Cambridge, UK: Cambridge University Press.

28. Palombit RA, Seyfarth RM, Cheney DL. 1997 The adaptive value of 'friendships' to female baboons: experimental and observational evidence. Anim. Behav. 54, 599-614. (doi:10.1006/anbe. 1996.0457)

29. Baniel A, Cowlishaw G, Huchard E. 2016 Stability and strength of male-female associations in a promiscuous primate society. Behav. Ecol. Sociobiol. 70, 761-775. (doi:10.1007/s00265-016-2100-8)

30. Zipple MN, Grady JH, Gordon JB, Chow LD, Archie EA, Altmann J, Alberts SC. 2017 Conditional fetal and infant killing by male baboons. Proc. R. Soc. B 284, 20162561. (doi:10.1098/rspb.2016.2561)

31. Huchard E, Charpentier MJ, Marshall H, King AJ, Knapp LA, Cowlishaw G. 2013 Paternal effects on access to resources in a promiscuous primate society. Behav. Ecol. 24, 229-236. (doi:10.1093/ beheco/ars158)

32. Weingrill T, Lycett JE, Henzi SP. 2000 Consortship and mating success in chacma baboons (Papio cynocephalus ursinus). Ethology 106, 1033-1044. (doi:10.1046/j.1439-0310.2000.00616.x)

33. Palombit RA, Cheney DL, Seyfarth RM. 2001 Female-female competition for male 'friends' in wild chacma baboons, Papio cynocephalus ursinus. Anim. Behav. 61, 1159-1171. (doi:10.1006/anbe. 2000.1690)

34. Baniel A, Cowlishaw G, Huchard E. 2018 Contextdependence of female reproductive competition in wild chacma baboons. Anim. Behav. 139, 37-49. (doi:10.1016/j.anbehav.2018.03.001)

35. Cowlishaw G. 1997 Trade-offs between foraging and predation risk determine habitat use in a desert baboon population. Anim. Behav. 53, 667-686. (doi:10.1006/anbe.1996.0298)

36. Higham JP, Heistermann M, Ross C, Semple $S$, MacLarnon A. 2008 The timing of ovulation with respect to sexual swelling detumescence in wild olive baboons. Primates 49, 295-299. (doi:10. 1007/s10329-008-0099-9)

37. Altmann J, Altmann S, Hausfater G, McCuskey SA. 1977 Life history of yellow baboons: physical development, reproductive parameters, and infant mortality. Primates 18, 315-330. (doi:10.1007/ BF02383111) 
38. Alberts SC, Altmann J, Wilson ML. 1996 Mate guarding constrains foraging activity of male baboons. Anim. Behav. 51, 1269-1277. (doi:10. 1006/anbe.1996.0131)

39. Bates D, Maechler M, Bolker B, Walker S. 2014 Ime4: linear mixed-effects models using Eigen and S4. R package version 1.1-7. See https://cran.rproject.org/package-Ime4.

40. R Core Team. 2017 R: a language and environment for statistical computing. Vienna, Austria: $\mathrm{R}$ Foundation for Statistical Computing.

41. Gesquiere LR, Wango EO, Alberts S, Altmann J. 2007 Mechanisms of sexual selection: sexual swellings and estrogen concentrations as fertility indicators and cues for male consort decisions in wild baboons. Horm. Behav. 51, 114-125. (doi:10.1016/ j.yhbeh.2006.08.010)

42. Huchard E, Cowlishaw G. 2011 Female-female aggression around mating: an extra cost of sociality in a multimale primate society. Behav. Ecol. 22, 1003-1011. (doi:10.1093/beheco/arro83)
43. Palombit RA. 2003 Male infanticide in wild savanna baboons: adaptive significance and intraspecific variation. In Sexual selection and reproductive competition in primates: new perspectives and directions (ed. (B Jones), pp. 367-412. American Society of Primatologists.

44. Bowman LA, Dilley SR, Keverne EB. 1978 Suppression of oestrogeninduced LH surges by social subordination in talapoin monkeys. Nature 275, 56-58. (doi:10.1038/275056a0)

45. Huck UW, Lisk RD, Miller KS, Bethel A. 1988 Progesterone levels and socially-induced implantation failure and fetal resorption in golden hamsters (Mesocricetus auratus). Physiol. Behav. 44, 321-326. (doi:10.1016/0031-9384(88)90032-7)

46. Ims RA. 1990 The ecology and evolution of reproductive synchrony. Trends Ecol. Evol. 5, 135-140. (doi:10.1016/0169-5347(90)90218-3)

47. Dubuc C, Brent LN, Accamando AK, Gerald MS, MacLarnon A, Semple S, Heistermann M, Engelhardt A. 2009 Sexual skin color contains information about the timing of the fertile phase in free-ranging Macaca mulatta. Int. J. Primatol. 30, 777-789. (doi:10.1007/s10764-009-9369-7)

48. O'Connell SM, Cowlishaw G. 1994 Infanticide avoidance, sperm competition and mate choice: the function of copulation calls in female baboons. Anim. Behav. 48, 687-694. (doi:10.1006/anbe. 1994.1288)

49. Nunn CL. 1999 The evolution of exaggerated sexual swellings in primates and the graded-signal hypothesis. Anim. Behav. 58, 229-246. (doi:10. 1006/anbe.1999.1159)

50. Huchard E, Courtiol A, Benavides JA, Knapp LA, Raymond M, Cowlishaw G. 2009 Can fertility signals lead to quality signals? Insights from the evolution of primate sexual swellings. Proc. R. Soc. B 276, 1889-1897. (doi:10.1098/rspb.2008.1923)

51. Alberts SC, Fitzpatrick CL. 2012 Paternal care and the evolution of exaggerated sexual swellings in primates. Behav. Ecol. 23, 699-706. (doi:10.1093/ beheco/ars052)
9

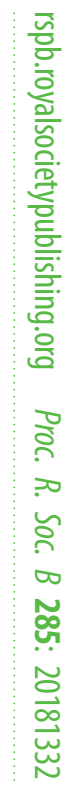

